perfect — in sentences such as “The bracing early-morning air would have invigorated Mary's senses" - soon begins to grate.

Emling's biography is the more thorough and complete work. It also frees us from the claustrophobic atmosphere of Lyme Regis, providing the context of discoveries happening elsewhere. Chevalier's tale glosses over most of Anning's later life. But so accurate was her fictional rendering that I felt I was reading the same book twice. Both works did, however, lack a gripping plot. Emling's solution was to incorporate peripheral dramas, such as natural disasters befalling Lyme Regis. Chevalier's strategy was to sneak Elizabeth Philpott into a key session of the Geographical Society and to give Anning a putative lover.

In the end, Anning's life story can offer no more than a pleasant but sedate read, either in fact or fiction. More evocative was the drama, brought out well in both works, of how her discoveries shook the world: leering, nightmarish monsters materializing from the clay and hinting at a world far more ancient, savage and uncaring than anyone could possibly have imagined.

Jennifer Rohn is a cell biologist at University College London, UK, and editor of LabLit.com.

Her first novel is Experimental Heart.

e-mail: jenny@lablit.com

\title{
History of the hard stuff
}

\section{Uncorking the Past: The Quest for Wine, Beer, and Other Alcoholic Beverages by Patrick E. McGovern \\ University of California Press: 2009. \\ 348 pp. \$29.95, £20.95}

Barley, wheat and grapes in the Middle East; rice, millet and hawthorn fruit in China; figs and dates in the Levant; sorghum and palm sap in Africa; maize, cacao, cactus fruit, manioc and pepper-tree fruit in the Americas; and everywhere, honey. All these substrates were used by early humans in their quest for alcohol.

In Uncorking the Past, biomolecular archaeologist and University of Pennsylvania museum director Patrick McGovern argues that the desire for alcohol is innate in humans and other primates. Moreover, he believes that "the uniquely human traits" of self-consciousness, innovation, the arts and religion have been "encouraged by the consumption of an alcoholic beverage". This is a difficult proposition to prove. In trying to do so, McGovern takes his reader on a world tour, examining the archaeological record for alcohol use across continents and cultures, searching for common themes that are indicative of universal use.

The earliest pottery artefacts with identifiable residues of a fermented beverage - arising from a mixed fermentation of rice, honey and hawthorn fruit - were found in China and date to 7000 BC. Three thousand miles away, in the Zagros mountains in western Iran, pottery dating to $3500 \mathrm{BC}$ has been found with residue of tartaric acid, indicating wine storage, as well as containers with a calcium oxalate 'beerstone' residue from barley beer. In Asia, Europe and the Americas, archaeologists have unearthed buildings that were constructed for the production and storage of various alcoholic beverages. And fermentation vessels and elaborate drinking sets are found in tombs of the rich and powerful across the world. Clearly, alcohol has been a part of human civilization for millennia. But has it played a part in the development of human culture?

McGovern narrates his thoughts in the first person, as if relating them to friends over a drink. He intertwines his own research findings - detailed in his earlier book, Ancient Wine with those of others, and tells stories of quests to recreate ancient beverages. He describes tasting 'Chateau Jiahu', a modern recreation of the earliest fermentation discovered in China; and the 'Phrygian Grog' he named 'Midas Touch', a fermented beverage based on wine grapes, honey and malted barley.
The residues of this were found in bronze containers in the burial chamber of a Phrygian king, perhaps Midas, near present-day

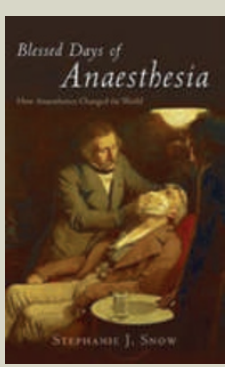

Blessed Days of Anaesthesia: How Anaesthetics Changed The World

by Stephanie J. Snow (Oxford Univ. Press, E9.99)

Stephanie Snow explores how early advances in

anaesthetics changed society. "[This] is not a real medical

history, nor is it seriously concerned with medicine or society beyond England and Scotland. But it seeks to link developments in anaesthesia with changing social, philosophical, scientific and religious attitudes in those countries," wrote John Carmody (Nature 456, 38; 2008).

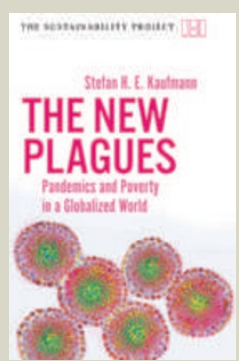

The New Plagues: Pandemics and Poverty in a Globalized World

by Stefan Kaufmann (Haus Publishing, £9.99)

An accessible and up-to-date look at diseases that are on the rise thanks to increased globalization. Describing the various strategies that agents such as microorganisms or prions might adopt, Stefan Kaufmann delves into the conflict between rich and poor in combating outbreaks, and looks at methods for containment. 
Ankara. For a general reader, the blend of fact and personal narrative is enticing, reminiscent of the mixed fermentations practised by our Neolithic ancestors; but some academics, thirsty for footnotes, may wish he had chosen a more traditional form.

McGovern begins by speculating about the role of alcohol in the Palaeolithic period, suggesting that its shamanic use, alongside other drugs, helped to develop religion and art - a proposition that is impossible to test conclusively. Neolithic and early Bronze Age cultures produced pottery and metal vessels, from which residues can be analysed. In most cases, the first fermentations were mixtures of grains, honey and wild fruit. Grains presented a problem to early brewers because the starch in the grains had to be converted to sugar before fermentation could begin. This was solved in various ways in different cultures: the use of enzymes in human saliva to break down starches is still applied in Africa and the Andes; malting and kilning of the grains is another technique, raising the possibility that beer came before bread; and the use of mould is often found in Asian rice-based brews.

Mixed fermentations, starting with higher sugar concentrations and natural yeast derived from honey and fruits, resulted in beverages of higher alcohol content than those based solely on grains. As cultures gained experience, most moved to single fermentations - beer, fruit wines or mead - with one type of beverage gaining dominance. The social importance of these beverages is reflected in the elaborate nature of fermentation vessels and drinking sets found in tombs in Asia, Europe and the Americas. Alcohol's widespread use is attested in paintings on vessels depicting communal sipping of one drink through shared straws, a scene repeated across many cultures.

The most powerful argument for alcohol as a force for innovation and social development is the claim that the initial domestication of many grains was "motivated by a desire to increase alcoholic-beverage production", rather than to provide more food. However, only one example is explored in the book, namely the suggestion that humans were

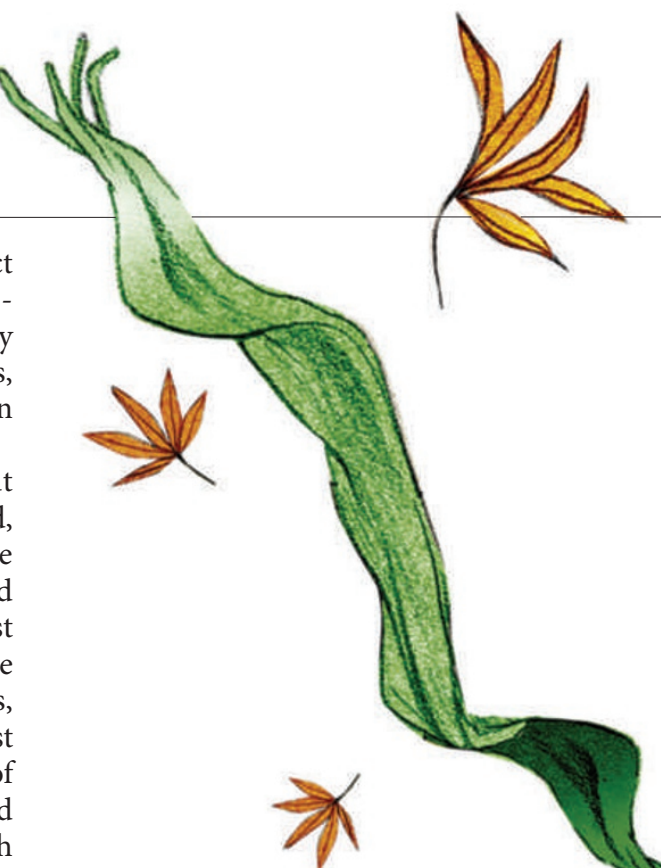

originally attracted to teosinte grass and maize (corn) because of the fermentable sweet syrup in its stalks, and that our selection of the seed kernels of these plants for food followed only afterwards.

The broader case centres on alcohol's perceived ability to spark creativity in some individuals, encouraging them to progress beyond tradition. In the words of William James: "Sobriety diminishes, discriminates, and says no; drunkenness expands, unites and says yes." Although that general argument resonates with this reviewer, McGovern doesn't give any specific examples of social advancement through alcohol consumption.

Uncorking the Past doesn't prove McGovern's thesis that alcohol has been a significant force in human development, but it does demonstrate that fermented beverages have been incorporated into the fabric of society for millennia. For some, taking a 'cup of kindness' may be a ticket to altered consciousness; for most, it invites sociability through temporary effects to our

limbic system. Both outcomes are sorely needed in today's society.

Jim Lapsley is adjunct associate professor in the Department of Viticulture and

Enology at the University of California, Davis, 1 Shields Avenue, Davis, California 95616-5270, USA.

e-mail: jtlapsley@ucdavis.edu

\section{Living by the calendar}

\section{The Seasons of Life: The Biological Rhythms that Living Things Need to Thrive and Survive \\ by Russell Foster and Leon Kreitzman \\ Profile Books/Yale University Press: 2009 320 pp. $€ 20 / \$ 28$}

Much of biology is governed by the seasons. Reindeer seasonally adjust the colour of their eyes for better vision; newborn warblers are programmed to fly from Europe to an unknown destiny in Africa; hibernators turn down their internal thermostat for six months of the year. Most biologists would jump to unravel such seasonal feats if the time constraints were not so forbidding. Russell Foster and Leon Kreitzman lament in their latest book the slow pace of research on annual rhythms in biology. Yet their fascinating story impresses with its wealth of facts and splendid overview.

The Seasons of Life follows on from the authors' previous collaboration, The Rhythms of Life (Profile Books, 2004). Russell Foster, a professor in circadian neuroscience at the University of Oxford, UK, is an eminent scientist in the field of chronobiology, and a passionate one. He helped to discover specific ganglion cells in the mammalian retina that perceive light intensity and are instrumental in synchronizing biological clocks. Kreitzman is a science journalist with a lucid pen. Together, they paint a broad perspective on the functions and mechanisms of biological calendars.

The authors dedicate five chapters to the adaptation of animals and plants to the

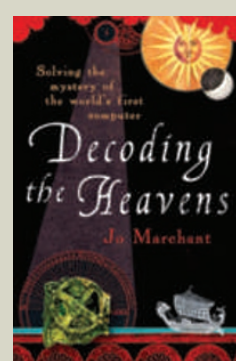

Decoding the Heavens: Solving the Mystery of the World's First Computer

by Jo Marchant (Windmill Books, $€ 8.99$ )

The 2,000-year-old Antikythera Mechanism was found in 1901, but its significance was only recently revealed. "[This] gripping and varied account will propel the mechanism to greater fame, although it may never achieve the celebrity of the Rosetta Stone that it probably deserves," argued Andrew Robinson in his review of the hardback edition (Nature 455, 867-868; 2008).

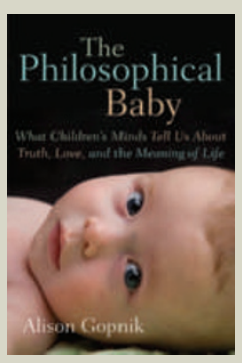

The Philosophical Baby: What Children's Minds Tell Us About Truth, Love, and the Meaning of Life

by Alison Gopnik (Bodley Head, E14.99) Alison Gopnik's well-written book is an unusual look at the conscious mind. Drawing on research and her own pioneering studies, she reveals that processes in a baby's mind can be as complicated as those in the minds of adults, and asks what brain development can teach us about humanity. 